ticularly rich in examples of methods of calculating which have long since disappeared from our arithmetics, and, as the author points out, some of these are, by no means, inferior to those now used. Such examples make the history of arithmetic very real to one. The sections entitled 'Causes which checked the growth of demonstrative arithmetic in England,' 'Reforms in arithmetical teaching,' and 'Arithmetic in the United States,' show forcibly the stagnation which results in regarding it not as a demonstrative science, but merely as an art of calculation.

The accounts of modern synthetic geometry and of non-Euclidean geometry (pp. 252-275) seem well chosen. It is necessary for teachers of geometry to have a broader view of their subject than is afforded by the typical text-book.

Having called attention to some of the merits of Professor Cajori's work, it is unfortunately necessary now to note some of its defects. The inconvenient method of introducing an abbreviation, the first time a work is cited, to be used for it subsequently, we trust will in future editions be remedied by a table at the end of the volume. It is confusing, if one is not certain of their identity, to have 'Ptolemy' and 'Ptolemæus' used indiscriminately. In the statement that " $\sqrt{2}$ cannot be exactly represented by any number whatever" (p. 51), the word rational has, of course, inadvertently been omitted. Foot-note 3, p. 72 , is very indefinite in its present form. Referring to remarks at the top of page 74 , we quite agree with the author that rigor in geometry demands the proof of the possibility of all constructions before they are used. For example, that the circumference of a circle admits of being divided into any number of equal parts should be shown (which involves no difficulty) before considering regular inscribed polygons in general. The example of the text leads one to suppose that rigor demands our ability to construct (subject, in fact, to the arbitrary condition of having only ruler and compass) every inscribed polygon we may wish to use.

The material of the volume in places shows lack of coordination and incomplete moulding into an organic whole. One feels at times lost in a maze of fact. We are given part of the biography of Leonardo of Pisa on page 119 and part on page 134. The origin of the word 'sine' is found on page 124 and again on page 130. On page 75 and again on page 78 we are told of the tomb of Archimedes.

In the foot-note 1 , page 160 , the conclusion that the base of Napier's logarithms is $e^{-1}$ is erroneous, and it does not follow from what precedes it. If we define the logarithm of $x$ with respect to the constant base $b$, by the equation $x=b^{\log x}$, then the numbers discovered by Napier are not logarithms; but if $b$ is not restricted to be constant, the above equation defines Napier logarithms when

$$
b=10 \frac{7}{\log x} \div C^{\left(\frac{x}{10}\right)^{7}}
$$

(Hagen, Synopsis der hoeheren Mathematik I., p. 107.) To define the base of Napier's logarithms as the number whose logarithm is unity is in this case misleading. The term is, how . ever, so used by Cantor (Geschichte der Mathematik, II., p. 672), who gives its value to be

$$
10^{7} \div C^{\left(\frac{x}{10}\right)^{7}}
$$

\section{Purdue University.}

E. M. BLAKE.

\section{Die Bedingungen der Fortpflanzung bei einigen} Algen und Pilzen. Von Dr. George Klebs. Jena, Gustav Fischer. 1896. Pp. i. +543, 3 plates.

This work of Dr. Klebs' is an important contribution to the physiology of reproduction. As its title indicates, the experiments were conducted for the purpose of determining the conditions of reproduction in certain algæ and fungi. A preliminary account of some of this work has been published in earlier contributions. The earlier experiments have been amplified and extended to a number of additional plants, and the present work details carefully his later experiments and presents the philosophy and deductions of all his work upon this topic. It is a remarkable work, alike for the painstaking conduct of the experiments, the precautions against error, the important results obtained and the cautious generalizations upon the relations of the different kinds of reproduction to environment. Not only is the work one of great interest to the student of develop- 
ment and to those interested in the theoretical questions of reproduction, but it is one which will be a great aid to teachers who wish to supply material of these lower forms of algæ to their classes in a condition in which these processes of reproduction can be observed. This is especially so in the case of certain species of Vaucheria, Hydrodictyon, Oedogonium and others, since the conditions have been determined under which one can with certainty bring the material to the production of zoospores, or to the development of sexual organs within a reasonable limit of time.

His most extended experiments were conducted upon species of Vaucheria, especially upon Vaucheria repens, clavata and sessilis, or upon the composite species Vaucheria sessilis, as some would treat it. Klebs would, however, treat these three forms as species, and it is interesting to see how the reactions of these three forms toward various conditions of environment and artificial treatment give support to the view that they may be regarded as species, and we are promised a thorough-going revision of the species of Vaucheria from the hand of one of Dr. Klebs' students.

The experiments cannot be given in detail, but under the head of the asexual reproduction through zoospores the methods employed were similar to those noted in 1892. Plants cultivated in the light and in moist atmosphere, on being transferred to water produce numerous zoospores; cultivated in a 0.2 per cent. to 0.5 per cent. nutrient solution (inorganic salts) in the light, on being transferred to pure water produce zoospores. On the other hand, cultures in water, or in a 0.1 per cent. to 0.2 per cent. nutrient solution, produce zoospores on simply being darkened. The development is especially active when the first or second method is combined with the third. In studying the conditions which influence sexual reproduction he found Vaucheria repens the best subject, though any of the species studied could be brought with certainty in artificial cultures to form sexual organs. For example, threads of Vaucheria repens placed in a 0.2 per cent. to 0.4 per cent. cane-sugar solution form sexual organs with the greatest certainty in four to five days. In studying the influence of light he found that it acts in a two-fold manner. Through the assimilation of $\mathrm{CO}_{2}$ reserve material, in the form of organic compounds, which is necessary for sexual reproduction, is supplied, and the light also acts in a direct way stimulating the process. This was proved by growing cultures under conditions where an abundance of light was supplied, but the plants were deprived of the $\mathrm{CO}_{2}$ of the air, so that none or little carbon assimilation took place and no sexual organs were formed. Cultures, under similar conditions, in a cane-sugar solution, produced sexual organs, the reserve material here being supplied by the sugar solution. On the other hand, cultures in a cane-sugar solution in weak light or in darkness produced no sexual organs. The same results were obtained in cultures of other genera of algæ, and his conclusions that light acts in a twofold manner seem justified.

In studying the conditions which influence the male or female organs some interesting results were obtained, though no definite conclusions were reached regarding the relation between these two kinds of organs. Cultures in a thermostat at $25^{\circ}$ to $26^{\circ} \mathrm{C}$. showed a tendency to complete suppression of the oogonium or to a vegetative growth of the same, the number of oogonia in a group being not incresed, while the antheridia were increased in number in some cases as much as five- to sevenfold. Cultures under air pressure of $120 \mathrm{~mm}$. gave similar results.

In his studies of Drapernaudia glomerata he discovered microzoospores and observed their conjugation to form zrgospores. Pringsheim, in 1860 , first observed resting cells, and speaks of the formation of microzoospores, though he does not describe them. Klebs first observed them in 1894. Algæ were taken from a cold standing culture and placed in a 2 per cent. cane-sugar solution in the heated laboratory. After twenty-four hours zoospores were formed, and after forty-eight hours microzoospores appeared. The microzoospores are oval to spherical and about half the size of the zoospores, and are four ciliate. The red-eye spot is near the base of the body while in the zoospores it is situated at the upper third. Many of the microzoospores form resting spores parthenogenetically, though, as stated above, Klebs was 
able to observe certain of the resting cells formed by the conjugation of two microzoospores.

In his studies upon Botrydium granulatum he determined by pure cultures that what has been regarded as a remarkable pleomorphic species really represents two distinct species. His attention was first called to this confusion by the difference in the cell structure of the various forms. In one the chlorophyll bodies are in the form of distinct discs, while in the other the chlorophyll is a single connected plate. In one the cells form a fatty oil but no starch, while the other possesses amylon grains and starch bodies, their structure being like that of the cell of Hydrodictyon. One of these plants is a true Botrydium, while the other is the Protococcus botryoides, described by Kuetzing in 1845, and in 1855 Cienkowski correctly described its development. Since the genus Protococcus is untenable, Klebs proposes the name of Protosiphon botryoides for this plant.

He takes occasion to deplore the tendency of some algologists to repeat in the case of the algæ the pleomorphic craze which once brought such confusion to bacteriology and mycology, citing especially Hansgirg, in 1855, and the more recent work of Borzi and Chodat, who claim to have connected a large number of genera in the form cycle of one species. $\mathrm{He}$ points out that these investigators did not use pure cultures and were thus led to include in the form cycle different genera appearing in the culture. It has been held by some that if filamentous algæ possess protococcoid forms in one stage of development, then all protococcoid forms are states of filamentous algæ. It is impossible to distinguish the swarming gametes of Chlamydomonas and Ulothrix, still it does not follow that Chlamydomonas belongs to Ulothrix. He insists that in studies of development pure cultures should be used, though pure cultures in the sense in which they are made in bacteria and the fungi cannot be made. Pure cultures and continuity of observation, especially in connecting different stages, should be substituted for mixed cultures and discontinuous observations.

Space will not permit a discussion of his experiments upon other genera of algæ and the fungi, but the following outline of his experiments upon Vaucheria will give an idea of the thorough and comprehensive manner in which his work was conducted.

I. The asexual reproduction through zoospores of Vaucheria repens and clavata.

1. Influence of nourishment.

2. Influence of dampness.

3. Influence of light; of darkness; of weak light; of the rays of the spectrum; of light intensity; of carbon assimilation.

4. Influence of temperature; low temperature; high temperature; mean temperature and variations of temperature.

5. Influence of the chemical peculiarities of the medium.

A. Inorganic compounds; effect of nutrient salts; change from nutrient salts to water.

B. Organic compounds; cane sugar; camphor.

C. Osmotic value of the compounds.

D. Influence of acid or alkaline reaction.

E. Influence of oxygen; influence of air pressure; of rarified air.

F. Influence of flowing water; of friction; of temperature; of oxygen and nutrient salts.

II. The asexual increase in the case of other species of Vaucheria: Vaucheria ornithocephala; aplanospores of $V$. geminata; conditions of their formation; aplanospores of $V$. racemosa, uncinata.

III. The sexual reproduction of Vaucheria.

1. Influence of light.

A. Effect of light as a means of nourishment.

B. Influence of light intensity.

C. Significance of colored light.

2. Influence of dampness.

3. Influence of temperature.

4. Influence of chemical peculiarities of the medium.

5. Influence of oxygen.

6. Influence of flowing water.

7. Upon the relation of the male and female sex.

Geo. F. Atkinson.

CoRnell University.

Codice Messicano Vaticano, No. 3773. Edizione Del Duca de Loubat. Roma. 1896.

In the native literature of America that which was the product of aboriginal authors, the pictographic manuscripts, or 'codices,' as they are called, of Mexico and Central America, hold the first rank. Quite a number of them, though generally in an imperfect condition, have been preserved which date from before the 